https://doi.org/10.7203/Normas.2.465

\title{
PARA UNA CARACTERIZACIÓN DE LA VARIEDAD CUBANA DEL ESPAÑOL EN LA DÉCADA DEL CUARENTA DECIMONÓNICA. COMENTARIO DE CARTAS
}

\author{
TOWARDS A FORTIES NINETEENTH CENTURY CUBAN SPANISH \\ CHARACTERIZATION. COMMENTARY OF LETTERS
}

\author{
Marlen A. DOMÍNGUEZ HERNÁNDEZ \\ Universidad de La Habana
}

\section{RESUMEN:}

En este artículo se discute si la variedad cubana de la década del 40 del siglo XIX está ya suficientemente diferenciada, y se trata de demostrar, a partir del estudio de un grupo de rasgos tipificadores en una muestra de cartas, que los procesos más importantes, de modo general, no han concluido completamente su cambio.

PALABRAS CLAVE:

Español en Cuba, lingüística histórica, cartas, siglo XIX.

\section{ABSTRACT:}

This article discusses whether the Cuban variety of 40s of XIX century is already sufficiently differentiated, and it is shown, from the study of a group of typifying traits in a sample of letters that the most important processes, in general, have not fully completed their change.

KEY WORDS:

Cuban Spanish, historical linguistics, letters, XIX century. 


\section{INTRODUCCIÓN}

¿Podría caracterizarse el español de Cuba de la década del cuarenta decimonónica como una variedad geolectal fuertemente diferenciada de otras? ¿Se detectan en él la mayoría de los rasgos que se emplean hoy para caracterizarlo? ¿Los fenómenos que lo singularizan se encuentran ya en su total plenitud? Con la revisión de 16 cartas de este período continuamos, lentamente, el proceso de comentario de textos para la descripción del proceso evolutivo del español en Cuba. Para ello se tomarán como norma de referencia las características que después se asientan y se describen como tipificadoras de esta variedad.

Se escoge este siglo por estar demostrada su relevancia para el análisis lingüístico, y porque hay consenso, igualmente, en su importancia para la historia de nuestro archipiélago.

Las cartas objeto de análisis son privadas, bien transaccionales, bien comunicacionales o mixtas ${ }^{1}$, de personas de posición social media o acomodada, pero no de las más sobresalientes de entre ellas, para garantizar que puedan aparecer deslices o cacografías y evitar en lo posible los afanes de las fuertes voluntades estilísticas. Es decir, se prefirieron los enunciadores menos originales, pero nacidos en Cuba o que habían venido al país desde muy jóvenes.

En relación con la tradición escrituraria epistolar, en el siglo anterior la norma de referencia para la escritura de las cartas estuvo representada por el Nuevo estilo y formulario de escribir cartas misivas (1701), colección de modelos de cartas no auténticas, estereotipados tanto en el esquema estructural como en las situaciones que tipologizaba ${ }^{2}$. Pero ya a partir de 1803, con la Retórica epistolar, ó arte nuevo de escribir todo género de cartas misivas y familiares; con exemplos de los autores mas célebres, extrangeros y nacionales, de A. Marqués Espejo, se busca librar a la epístola de ataduras convencionales o retóricas, según la tendencia de los franceses y especialmente de Madame de Sévigné.

Aunque los residentes en Cuba, criollos o peninsulares, no hubieran tenido acceso a ninguno de los dos tratados de primera mano, cabe pensar que su influjo pudo llegar a nuestras tierras simplemente por la propia práctica escritural.

\footnotetext{
${ }^{1}$ Las cartas son trasuntadas. No desconocemos el problema que ello supone para la fiabilidad de estos comentarios, pero se ha realizado un cotejo entre la edición patrocinada por Joaquín Llaverías en 1938 y la compilada y anotada por Sophie Andioc en 2002, ambas elaboradas sobre originales. En cualquier caso, este trabajo puede ser un primer paso para una búsqueda más adecuada.

2 J. Cadalso, Cartas marruecas, carta LXXXIX; Londres, Tamesis Books, 1966, p. 198, en Sánchez Espinosa (2001).
}

NORMAS. REVISTA DE ESTUdIOS LINGÜÍSTICOS HISPÁNICOS, NÚMERO 2 (AÑO 2012):

http://www.uv.es/normas 
Así, las cartas del siglo XIX se irían modificando en busca de sentimiento, sinceridad, brevedad e incluso originalidad ${ }^{3}$, a partir de las preceptivas explícitas, y de las recopilaciones de textos auténticos de grandes personalidades ${ }^{4}$. Esta orientación podría haber favorecido más que la anterior la aparición de formas del coloquio oral.

En cuanto a las bases teóricas y la metodología para el comentario de los textos, además de la bibliografía tradicional consignada en la lingüística histórica, nos centramos en enfoques de Vaquero (2006) y Sánchez Méndez (2006) y particularmente se han tomado en este caso como referencias un material de 2010 (Pons Rodríguez) y uno de 2011 (Ramírez Luengo). El primero, porque pretende, precisamente, establecer ciertos algoritmos de análisis de textos para fines lingüísticos; el segundo, porque se aplica a documentos americanos de los siglos XVIII y XIX. Con ese instrumental procedimos a la revisión de nuestras cartas.

Conviene aclarar que lo que se presenta a continuación no es la descripción exhaustiva de cada una, sino un conjunto de generalidades extraídas de aquel análisis, así como la mención a casos aislados de algún fenómeno, que puedan resultar de interés.

Dirigidas todas a Domingo del Monte, quien fuera un mecenas de la literatura cubana en gestación, cabe esperar que los destinadores de estas misivas, once hombres del siglo XIX cubano ${ }^{5}$, se esforzaran por producir su mejor escritura. Por ello, si aparece

${ }^{3}$ El propio Sánchez Espinosa menciona los consejos contenidos en ciertos autores sobre la necesidad de adecuación a los interlocutores, registros y situaciones, y sobre los modelos de cartas de personalidades destacadas.

${ }^{4}$ En general se comprueba en España un gusto por publicar cartas, que sin duda habrá tenido una repercusión en esta tradición discursiva en la colonia.

\begin{tabular}{|c|c|c|c|c|c|c|c|c|c|c|c|c|}
\hline \multicolumn{13}{|c|}{ Textos objeto de estudio } \\
\hline \multirow[t]{2}{*}{$\mathrm{N}$} & \multirow[b]{2}{*}{ III } & \multicolumn{6}{|c|}{ Destinadores } & \multirow{2}{*}{$\begin{array}{l}\text { Lugar } \\
\text { s.l. }\end{array}$} & \multicolumn{2}{|c|}{ Fecha } & \multirow[b]{2}{*}{1841} & \multirow{2}{*}{$\begin{array}{l}\text { Relación } \\
\text { amigo }\end{array}$} \\
\hline & & José & Braulio & de & Torres & & & & 12 & enero & & \\
\hline 2. & VI & A.M. & de & Escoved & & & & s.l. & s.f. & & & amigo \\
\hline 3. & VII & Francisco & Garnica & & & & & Cárdenas & 1 & febrero & 1841 & negocio \\
\hline 4. & $\mathrm{X}$ & Francisco & Garnica & & & & & Cárdenas & 19 & febrero & 1841 & negocio \\
\hline 5. & XII & Anastasio & de & Orozco & $y$ & Arango & & $\begin{array}{l}\text { Puerto } \\
\text { Príncipe }\end{array}$ & 27 & febrero & 1841 & amigo \\
\hline 6. & XIII & Anastasio & de & Orozco & $y$ & Arango & & $\begin{array}{l}\text { Puerto } \\
\text { Príncipe }\end{array}$ & 6 & marzo & 1841 & amigo \\
\hline 7. & XXII & José & Miguel & de & Angulo & $y$ & Heredia & Matanzas & 2 & abril & 1841 & amigo \\
\hline 8. & XCIII & Domingo & André & & & & & Habana & 12 & julio & 1843 & amigo \\
\hline 9. & XCIV & Gonzalo & Aldama & $y$ & Alfonso & & & Guanabacoa & 13 & julio & 1843 & cuñado \\
\hline 10. & XCVIII & Miguel & de & Aldama & $y$ & Alfonso & & Habana & 24 & julio & 1843 & cuñado \\
\hline
\end{tabular}


algún rasgo no canónico o alternante, puede interpretarse como un efecto de expansión u obsolescencia que debe observarse atentamente.

De otra parte, no todos los autores de las cartas consideran a Del Monte en tanto promotor literario, pues algunos tienen con él relaciones de tipo económico. También se encuentran cartas de familiares consanguíneos o por afinidad, en que la afectividad puede matizar otras consideraciones.

Como Del Monte se halla en el exterior buena parte del período considerado, algunos se ven obligados a describir la situación de la Isla, lo que conviene también a nuestro objetivo, y nos sitúa en un período entre 1841 y 1843, marcado por el avance de la producción azucarera, la construcción del ferrocarril, las sublevaciones de esclavos, la no total radicalización de los criollos acomodados a favor de la abolición, la búsqueda de inmigración blanca, y la emigración de personas de algunos sectores hacia el exterior, presionados por la dura política colonial.

Las cartas provienen, esencialmente, de personas de parte de la zona occidental del país (Habana y Matanzas) y de la central correspondiente a Camagüey, reputada como el área más conservadora de las que pueden delimitarse en Cuba; por ende, los usos de la zona más oriental no estarían representados.

\section{COMENTARIO ORTOGRÁFICO-FONÉTICO}

Los textos se caracterizan por la frecuente presencia de abreviaturas, la mayoría formularias o de conocimiento general: mi S. padre; att ${ }^{o}$; SS.; Q. B. S. M.; V.; D. (mi señor padre, atento, seguro servidor, que besa su mano, usted, don).

\begin{tabular}{|c|c|c|c|c|c|c|c|c|c|c|c|}
\hline 11. & $\mathrm{Cl}$ & Anastasio & de & Orozco & $y$ & Arango (Tatao) & $\begin{array}{l}\text { Puerto } \\
\text { Príncipe }\end{array}$ & 13 & agosto & 1843 & amigo \\
\hline 12. & CV & Antonio & del & Monte & $y$ & Tejada & Guanabacoa & 1 & setiembre & 1843 & primo \\
\hline 13. & CXIX & Miguel & de & Aldama & $y$ & Alfonso & Habana & 9 & $\begin{array}{l}\text { noviembr } \\
\mathrm{e}\end{array}$ & 1843 & cuñado \\
\hline 14. & CXXI & José & Mayol & & & & Habana & 19 & $\begin{array}{l}\text { noviembr } \\
\text { e }\end{array}$ & 1843 & amigo \\
\hline 15. & CXXVI & Antonio & del & Monte & $y$ & Tejada & Havana & 1 & diciembre & 1843 & primo \\
\hline 16. & CXXVII & Manuel & del & Monte & & & Habana & 2 & diciembre & 1843 & sobrino \\
\hline
\end{tabular}


El uso de signos de puntuación, y sobre todo de tildes, no es estable. Aunque escasas, se encuentran algunas muestras de hipo- e hipersegmentación: aconsecuencia, sinembargo, alménos.

En cambio, la ortografía que exhiben las cartas analizadas, de modo general, es ya la moderna, normada en 1815 y oficializada en España precisamente por la época de que datan estos documentos.

En cuanto a la representación de vocales plenas y satélites se destaca, sin embargo, la conservación de algunas ocurrencias de $\langle\mathrm{i}\rangle$ para representar /i/ morfemática, o la semivocal en monosílabos: mui, $\boldsymbol{i}$, y alguna eventual presencia de $\langle\mathrm{y}\rangle$ medial: bayladoras.

Muy escasas son las ocurrencias de conservación de $\langle q u>$ ante $<a>$ acentuada: qual, quatro, o de <ss>: assi, y se reporta alguna <qu> ante $e, i$ : frequentemente.

Es de interés la presencia de <h> expletiva: contrahe, cohordinan, hallanar, harneses, henmoesidos indicativa de hiato, pero puede tratarse también de una ultracorrección o simples inseguridades en el dominio del código. A esta última causa se atribuye la ausencia del grafema en casos de cero fónico: alaja, proivo.

Alternan la $\langle\mathrm{g}\rangle$ y la $\langle\mathrm{j}>$ para la representación del fonema fricativo laringal $/ \mathrm{h} / \mathrm{o}$ velar $/ \mathrm{x} /$ si lo hubiere, pero no siempre según el cánon, que disponía la $\langle\mathrm{j}\rangle$ ante cualquier vocal, excepto por restricciones etimológicas: protejerlas, ageno, deges, viage, gefe. Aparece, muy raramente, la grafía tradicional $\langle\mathrm{x}\rangle$ con este valor: exemplar, relox. Muchos de estos casos resultan de inseguridad en el dominio del código, o representan usos arcaizantes.

La frecuente alternancia de $\langle\mathrm{b}\rangle$ y $\langle\mathrm{v}\rangle$ puede interpretarse, además, como evidencia del betacismo que desde antiguo se ha establecido en la historia del español: fabor, bestirme, desvaratando, atrebido, iva, vicho.

No se documentan alteraciones del vocalismo átono, ni fenómenos de diptongación, monoptongación o métatesis $^{6}$, descritos para nuestra zona dialectal americana $^{7}$ salvo escasos ejemplos: sostituistes.

El rasgo ortográfico con derivación fonética más representado en la muestra es la alternancia de las grafías $\langle\mathrm{s}\rangle,\langle\mathrm{c}\rangle,\langle\mathrm{z}\rangle$, con ocurrencias en la mayoría de las cartas: inutilisen, ofenza, remicion, cajonsito, antisipadora, pacear, realisar, posilga,

${ }^{6}$ Las alternancias de vocales átonas se documentan hoy como fenómeno rural (Montero, 2007). Las metátesis se vinculan también a sociolectos bajos. Lipski (1994) no reconoce las modificaciones del vocalismo átono para Cuba. En cambio los fenómenos de diptongación y monoptongación son frecuentes y no marcados en la oralidad, si bien no aparecen en los textos escritos más que como cacografías o representaciones literarias.

${ }^{7}$ Aleza y Enguita (2002). 
comicion, reselos, hise, colonisacion y que pone de manifiesto la no distinción entre /s/ y $/ \theta /$. El predominio estadístico de las formas con $\langle\mathrm{s}\rangle$, además de los datos ya conocidos por la investigación, por ejemplo Choy (1999), Gutiérrez (2006) y Gosende (2007) fundamentan la no distinción como seseo.

No contamos con evidencias sustanciosas para conocer el estado del fenómeno de lenición y pérdida condicionada de la /-s/ distensiva, documentado para las Antillas y para Cuba en particular, prácticamente en toda la bibliografía, como en Lipski (1996), López Morales (1992), Aleza y Enguita (2002), Frago y Franco (2003), en los trabajos de Guitart (1978); Figueroa, Dohotaru y Noroña (1992) o Montero (2007), por citar textos ilustrativos de diferentes épocas, características y procedencias. Sin embargo, algunos datos en las cartas, si no se trata de simples lapsus calami, podrían ser testimonios de esta variación: leØ desea...tu primo, las ocurrencia Ø, han sido cogidoØmuchos, reciba unaØ mil espresiones, haberleØ desconcertado el plan que se propusieron.

Las alternancias $\langle 11\rangle\langle\mathrm{y}\rangle$ que documentarían el yeísmo son, en cambio, más escasas: lla, hallan (permitido) ${ }^{8}$, proyecto / prollectos (en la misma carta), lo que se compadece con otros estudios tanto para Cuba como para otras zonas americanas (Choy 1999; Gutiérrez, 2006; Ramírez Luengo, 2011).

La simplificación de grupos consonánticos ${ }^{9}$ (/ks/, /bs/, /s:/, /ps/, /pt/) en el habla se testimonia a través de la sustitución de la grafía $\langle\mathrm{x}\rangle$ por $\langle\mathrm{s}\rangle \mathrm{o}\langle\mathrm{z}\rangle$ para la representación de /ks/ > /s/: esplicarte, espresiones, estinguir, estenso, estramuros, ezequias y de $<\mathrm{s}>$ en lugar de $<\mathrm{sc}>$ para /s:/ > /s/: pisina; o <s> para representar /bs/ > /s/: ostaculos, y se documenta en la bibliografía como parte de la tendencia general hispánica hacia la sílaba abierta $\mathrm{CV}$, y en nuestra sintopía en correspondencia con el tratamiento del consonantismo distensivo.

Igualmente se documentan otros procesos de retraso consonántico como en <ct> para representar la evolución /pt/ > /kt/: adoctar (velarización de labial) ${ }^{10}$, o la

${ }^{8}$ A este respecto es de interés el comentario metalingüístico de J. Llaverías, quien publica las cartas en 1938, y se refiere al vocablo cullují, empleado en una de ellas, de este modo: En Cuba, especie de pedernal. Los cubanos usan la frase de ser un cuyuji para demostrar que uno es muy fuerte (T. V, p. 120). Además del comentario del conjunto estable cubano, puede notarse la reescritura de la palabra con $\langle\mathrm{y}\rangle$. En una carta, no considerada para la muestra por estar incompleta, alternan en el mismo texto llegua y yegua.

${ }^{9}$ En la bibliografía se reportan esencialmente los que incluyen /s/ o dentales.

${ }^{10}$ Este ejemplo y algunos semejantes podrían ser también interpretados como ultracorrecciones, en cuyo caso continuarían testimoniando el proceso de simplificación. Otra variante podría ser, para este caso específico, la etimología popular, pero no para otros como objecto, que es hiperculto y remite a su etimología.

NORMAS. REVISTA DE ESTUdIOS LINGÜÍSTICOS HISPÁNICOS, NÚMERO 2 (AÑO 2012):

http://www.uv.es/normas 
simplificación del grupo como en la grafía <c> que evidencia el paso de /ps/ a /s/: suscricion. Pero se recogen algunas formas arcaicas, con grupos conservados: objecto.

No se comprueban trueques ni otras alteraciones de líquidas, presentes hoy en algunas zonas del país y sociolectos ${ }^{11}$ y documentadas por varios autores como Lipski (1994) y López Morales (1971).

\section{COMENTARIO MORFOSINTÁCTICO}

Se documentan varios casos de derivación diminutiva, mayoritaria en -it- en nombres comunes: cajonsito, calladita, cajita, hermanito, perrito, encarguito, poquito, cosillas, y antropónimos: Rosita, Leonardito, pero como en ninguna de estas bases aparece $t$, no disponemos de datos para determinar la incidencia en la época del sufijo ic-, que se define estereotípicamente como más característico del español cubano. Estos diminutivos no lexicalizados pueden relacionarse con el tamaño, la edad o la corta duración, pero son más frecuentes los que presentan un valor atenuativo, intensificativo $\mathrm{y}$ en general connotaciones afectivas ${ }^{12}$. Las formas se concentran en las cartas familiares, y a falta de resultados más concluyentes, puede hablarse de un gusto por este procedimiento nominal.

En relación con otros formantes considerados por su frecuencia en el español de América, solo contamos con casos aislados, tales como el empleo de -ada- como sufijo colectivo: negrada, o la combinación del sufijo - ería con ciertas bases, que resulta en usos coloquiales: sinvergüencería.

Los textos dan fe de procesos gramaticales, tanto antiguos como decimonónicos, al ser transparentes en varios casos los elementos compositivos: con tigo, ferro carril.

Los pronombres personales clíticos aparecen en la posición para la cual se han estabilizado; a saber: antepuestos al verbo conjugado, pospuestos en el imperativo y las formas no personales del verbo: perderla, lo inutilisen, le conocí, esplicarte. En cambio, una carta que incluye la narración detallada de las circunstancias que dan lugar a un duelo y su desenlace, muestra enclíticos, con clara función estilística: encontrábase, preguntóle, respondiole, callóse, mientras otras partes del mismo texto presentan el uso

\footnotetext{
${ }^{11}$ Sobre el peso relativo del lambdacismo y el rotacismo en la zona occidental véase, por ejemplo, Dohotaru (2007) o Montero (1990).

${ }^{12}$ Sobre la interpretación de estos hechos véase RAE y ASALE (2009, pp. 627-662). Nos resulta de particular interés ver cómo lo que allí se propone como natural en la relación entre sustantivo contable / no contable y sufijo diminutivo tiene diferencias muy marcadas con el español de Cuba.
} 
normal. A pesar de tratarse de un ejemplo aislado para esta muestra, podría significar una pista de que el uso enclítico, vinculado a la narración, podría gozar de prestigio para ciertos registros.

Los pronombres $l o(s)$, $l a(s)$ y $l e(s)$ átonos de tercera persona se emplean en general según su índole etimológica (Lipski, Ramírez Luengo), respectivamente OD: lo trajo, colocarlo consigo, mandartelo, la hicieron, y OI: les dio a conocer a los fieros cántabros que..., le encuentras subscriptores. Sin embargo, se recogen algunos casos de le masculino de persona para el OD, antietimológico, pero sancionado por la Real Academia Española y recomendado como preferible hasta 1796 (Echenique, 2000), y por tanto prestigioso: le conocí, no le he visto, le tendrá presente, yo le respete. También se anota un caso de laísmo: devolviendola muy respetuosas atenciones.

Aunque no frecuente, se documenta le plural no concordado, fenómeno caracterizable como morfofonético (ut supra), en su relación con la aspiración o pérdida de la /-s/ distensiva, especialmente cuando es morfemática: prepararleø a nuestros hijos, a quienes leø..., y por tanto analizable en cuanto a la índole de los mecanismos de pluralización nominal, a través de procedimientos sintácticos y léxicos frente a los morfológicos.

En cuanto al pronombre personal sujeto de primera y segunda persona, aunque todavía no puede hablarse de un rasgo generalizado, se encuentran ejemplos en que se muestra la tendencia creciente a su explicitación: Yo diré siempre..., Yo no tengo ningún incoveniente..., Si $\boldsymbol{V}$. tiene la bondad..., nombrado yo ... para que dijera..., estar yo algo prevenido..., yo sé mui bien..., de modo que yo estaba dispuesto a ponerme en camino..., yo he sabido (entre paréntesis)..., yo creo..., ¿creerá $\boldsymbol{V} . q^{e}$. ayer..., iva yo a escribir a vmd. Puede advertirse que en algunos casos continúa tratándose de una forma enfática, y en otros es un desambiguador, y de esos valores puede extenderse a otros contextos. Respecto del orden en que aparecen en relación con el verbo en la oración interrogativa (Lipski, Gutiérrez), la muestra no ofrece datos para este análisis.

Asimismo, la escasez de ocurrencias no nos permite aquilatar el peso y valores de los dativos de interés (ambos se me han escusado).

En las formas de tratamiento ${ }^{13}$, incluso con los destinatarios más cercanos afectivamente, contienden el tú y el usted, lo cual revela una época de transición en este aspecto $^{14}$. Por ejemplo, con familiares consanguíneos, de cualquier edad, se emplea generalmente el tú, pero momentáneamente puede pasarse al usted en el mismo texto, lo que revela la persistencia de inseguridad: Amigo la Tabla Sinoptica se ha publicado y su resultado es satisfactorio para mi que la arregle y para $\boldsymbol{V}$. que la aprobo y apadrino. A tu salida estuve confuso. Entre amigos, el tratamiento depende del grado de cercanía y

\footnotetext{
${ }^{13}$ Véase, para la presentación general del problema, Fontanella de Weinberg (2000).

${ }^{14}$ Véase al respecto Domínguez (2004).
} 
del asunto de la carta. Las alternancias, al interior de un mismo texto, permiten aventurar que la abreviatura $v m d$. podría desatarse como usted. Hay testimonios de usos conservados de don y señor don como formas deferenciales, tanto alocutivas como referenciales, pero no se hallaron ocurrencias de vos.

Para la segunda persona del plural la forma representada es ustedes: los verificaban á nombre de Ustedes, salvo una ocurrencia de vosotros verbal: volved.

Se encuentran algunos casos de sintagmas con usted empleados como desambiguadores de los posesivos cortos de tercera persona: su Sra. de V. que se conservan hoy en varios lugares de América pero se han perdido en $\mathrm{Cuba}^{15}$.

Hay casos aislados interpretables como ocurrencias de omisión prepositiva ${ }^{16}$, aunque serían necesarios más datos para llegar a conclusiones fiables: me acordaba lo que me habias dicho, después que advertí las novedades, llegue á dudar si te irias por tu gusto y sobre todo para establecer fenómenos descritos para América como el queísmo y el dequeísmo.

En relación con los verbos, no puede deslindarse aún la neutralización entre formas simples y compuestas a favor de las primeras, que será característica de nuestra variedad; sin embargo, se encuentran algunos ejemplos de un proceso que podría estar más adelantado en la oralidad: parece que la Junta creyó que en la construcción de la doble carrilera..., recibí la tuya del 22.

En cambio, la regularización morfológica de la segunda persona singular del pretérito del indicativo, fenómeno hoy extendido en el coloquio oral pero no prestigioso, muestra algunas ocurrencias: mandastes, fuistes, sostituistes ${ }^{17}$.

Entre las formas del pretérito del subjuntivo es más recurrente -se que -ra: añadieses, siguieses, consultase ${ }^{18}$.

${ }^{15}$ Existe un chiste muy conocido al respecto en que se advierte que la forma más expedita de desambiguar hoy es pasar al tú. En los textos hay muestra de uso cortés, tampoco conservado, de demostrativo + posesivo: esta su casa, esta mi insinuación.

${ }^{16}$ Véase Gómez Torrego (2000), en que se atiende a los orígenes probables, la extensión y la distribución geográfica de estos fenómenos.

${ }^{17}$ Este fenómeno podría sugerir una hipótesis de ultracorrección ante una eventual pérdida de /-s/ distensiva, que habría que investigar con nuevas muestras.

${ }^{18}$ La distribución actual de estas formas está por estudiar, pero probablemente se relaciona con variables sociolectales y de registro. 


\section{COMENTARIO LÉXICO ${ }^{19}$}

Cabe referirse, ante todo, a la conciencia de los destinadores acerca de la índole del léxico que emplean. Es así que, a través de algunos recursos, marcan palabras como nuevas o diferentes: con el entrecomillado se presenta «equinoccio» (en el texto equinocio), voz técnica documentada desde el siglo XV; y de la reformulación se aclara un término a través de otro más extendido, contemporáneo o reconocido: canebá o sea cañamazo. Gaspar habla gordo como se dice p. ${ }^{r}$ acá es una referencia explícita de un uso que el destinador advierte como diferencial.

Mayoritariamente, sin embargo, aparecen sin ninguna marca piezas léxicas que aún hoy dibujan el panorama del español cubano, y que por tanto se sentían plenamente incorporadas para la época que se estudia: cubanismos como embullo, negrada, guajiro $^{20}$; de origen antillano o indoamericano en general: hicacos, bohío, batey, ácana o con marca de uso en esta región: hacendado, criollo.

Otras voces patrimoniales muestran los cambios semánticos que han sufrido en $\mathrm{Cuba}^{21}$ : ingenio (elipsis), dotación (especialización), estropeado (otra acepción, coloquial), barracones (otra acepción), y hay palabras allí empleadas, que se mantienen hoy, y que el DRAE no recoge: medio punto, canebá.

Desde nuestra perspectiva actual, un grupo no despreciable de piezas léxicas constituirían arcaísmos: algunos por la desaparición del referente (estramuros), por el desarrollo de la ciencia y la técnica (calenturas, flucción) y en general por los cambios en los hábitos y la vida: espresiones, libranza, soiré $e^{22}$ cullují, mejengue; líneas de carril, caja de azúcar, azúcar quebrado, cortar a facetas, casa de purga, camino de hierro, papel(es) público(s), sinvergüencería (coloquiales según el DRAE estos dos últimos), corrimiento de muelas.

Los conjuntos léxicos más o menos estables del tipo no decir esta boca es mía, ir buena la danza, ser como cullují, dar la patada la mula, tener entre ojos o enseñar las uñas, son representativos del coloquio oral, y algunos se mantienen en la modalidad cubana.

Finalmente, se encuentran algunas muestras de toponimia cubana que matizan los textos, tales como: Matanzas, Puerto Príncipe, Havana, Habana, Güines, Cardenas,

${ }^{19}$ Para la evolución léxico-semántica en el español de Cuba son imprescindibles las obras de Valdés Bernal (1974, 1986, 1990 y 2007), entre otros.

${ }^{20}$ Aparecen en el DRAE aún hoy con esta marca.

${ }^{21}$ Aparecen en el DRAE.

${ }^{22}$ Este préstamo del francés es muy del gusto del siglo XIX cubano, pero decae en el XX. 
Nuevitas, Guanabacoa, el Cerro, Camagüey, Marianao, Sabanilla, Merced. Como puede advertirse algunos de los topónimos son indigenismos, y todavía hay alguna vacilación en la grafía de Habana ${ }^{23}$.

En cuanto a los contenidos, pueden agruparse las palabras que describen mejor la época, desde la perspectiva económica relativas a la esclavitud y la producción del azúcar y el café, el miedo al negro y las alternativas que se proponen a su mano de obra; y desde la perspectiva política tales como abolicionista, insurrección, sublevación, independencia, alzamiento, Patria, destierro, etc. En cuanto a unidades de medida se documenta leguas, millas.

Son también caracterizadoras las expresiones contextuales, del tipo verlo en San Dionisio, que según el editor remite al centro siquiátrico de la época, y que ya no son transparentes para nosotros.

\section{ORALIDAD TRANSCRITA}

Los textos recogen algunas muestras de oralidad transcrita, en general bastante elaborada y canónica: ...le contesté con estas espresiones $=\langle\boldsymbol{D}$. Domingo Del Monte sabe cual es el aprecio que yo hago de su memoria, no necesita de estar presente $p^{a}$ que yo le respete: estas resoluciones son de mi á el y yo dare cuenta. Pero para desarmar á $\boldsymbol{V}$. de su defensa...», pero siempre pueden encontrarse fenómenos de interés. Tal es el caso, en este ejemplo, del uso del don referencial en la época, del tratamiento de usted y señor don alocutivos, la recurrencia del yo, el leísmo de persona, y la expresión de la superlatividad por repetición: poco valor, poco valor.

Predominan los trozos en estilo indirecto, que encubren más aún los rasgos del habla. Sin embargo, igualmente pueden hallarse algunas muestras útiles como: los demas me han preguntado que si se hallaba contento y si no decia nada de volver, en que se documenta la doble conjunción en la introducción de la interrogativa general.

${ }^{23}$ Sobre la grafía del topónimo Habana, véase la argumentación de Antonio Bachiller citada en Domínguez (2010). 


\section{LA TEXTURA DISCURSIVA}

Un aspecto de la textura discursiva: el de los marcadores y conectores; es decir, la expresión patente, sintáctico - semántica de las relaciones, y los medios por los que estas se concretan (Calsamiglia y Tusón, 2004: 245ss.), podría darnos aquí en qué medida las cartas consideradas se alejan de los moldes retóricos del XVIII, y se acercan a cierta oralidad elaborada (coloquio escrito) que nos ofrece pistas sobre el habla real.

Lo primero que cabe comentar es que en estas cartas decimonónicas cubanas son escasos los marcadores metatextuales, como conviene al carácter que ha adquirido este tipo, al menos para la muestra considerada, con el predominio de $y$ como aditivo y continuativo. Solo en casos de intercambios más formales, o de personas con mayor ilustración, se encuentra algún otro: en fin.

En cambio, los marcadores de operaciones discursivas tienen cierta mayor presencia: desde luego, por supuesto (de confirmación), o sea, es decir (de reformulación). Este análisis se dificulta también por el uso irregular o la ausencia de los signos de puntuación a que ya habíamos hecho referencia.

En la relación lógico - semántica entre los segmentos textuales predomina igualmente $y$, entre los aditivos; pero entre los contrastivos; pues entre los de base causal, y temporales como mientras tanto, entre pocos días... Sería útil un estudio más detenido de los valores pragmalingüísticos de estos conectores, sobre todo del pues, que será desplazado en nuestros usos por otras formas, y así podríamos seguir el camino de la reorganización de este subsistema en el español de Cuba.

Los de mayor interés para nuestro análisis son los marcadores «interactivos», que serían evidencias más ciertas de la oralidad. Sin embargo, de estos se localizan solo algunos pocos ejemplos: Esto es todo... (marcador de cierre); ¿Con que te vas a Europa? Bueno muy bien determinado... con el uso de la partícula ilativa conque ${ }^{24}$ en pregunta retórica, con valor de sorpresa o reproche ${ }^{25}$, y el empleo de bueno (marcador de transición, aclaración o toma de turno), cuya frecuencia se mantiene y es rasgo general del español.

\footnotetext{
${ }^{24}$ Soldados los elementos compositivos o no en la escritura.

${ }^{25}$ Menos habitual hoy en el coloquio oral cubano.
} 


\section{CONCLUSIONES}

La situación referida en cuanto a la relativa estabilidad del vocalismo átono, las evidencias de seseo, la simplificación de grupos consonánticos, el uso etimológico del pronombre átono de tercera persona, la frecuencia y la índole de la derivación no lexicalizada, así como los datos léxicos permiten afirmar el avance de una variedad singular en las zonas occidental y central de Cuba para la época de estas cartas, fuertemente emparentada con las hablas antillanas y a medio camino entre las peninsulares y las americanas continentales. De ello se infiere que, aunque el modelo de preferencia es el centro-norte-peninsular, la distancia entre esa norma y el habla real se incrementa ${ }^{26}$.

Sin embargo, se necesitarían más datos para verificar el grado de desarrollo de fenómenos hoy característicos tales como la lenición y pérdida condicionada de la /-s/ distensiva y otros de retraso consonántico, así como de sus consecuencias en cuanto a los procedimientos de formación de plurales; el uso de los pronombres sujeto de primera y segunda persona no enfáticos y su colocación preverbal en la oración interrogativa; los procesos de queísmo y dequeísmo y su valoración social, y la neutralización entre formas verbales simples y compuestas, con mayor frecuencia de las primeras. Su insuficiente presencia en la muestra puede interpretarse o bien como poco desarrollo de estos fenómenos en la realidad del habla, o bien por las restricciones sociolectales y estilísticas que los mantendrían fuera de la tradición escrituraria de personas de esta condición.

Probablemente los procesos relativos a la debilitación consonántica se hallaban más adelantados de lo que permiten afirmar nuestros datos, mientras que los preposicionales y pronominales seguirían un curso más lento, pero solo más búsquedas con materiales auténticos apropiados permitirán ir llenando las casillas vacías en este tránsito.

Por otra parte, no es evidente el peso que tienen las hablas subsaharanas en el desarrollo de esas tendencias, pues las más frecuentes se documentan desde épocas antiguas en la evolución peninsular de la lengua. Sin embargo, puede tratarse de fenómenos de concurrencia.

Tomando en cuenta el peso de unos y otros datos, sería evidente la pertenencia a la zona dialectal antillana, dentro del español americano, por el uso del tuteo, pero no suficientemente documentada en la muestra por el tratamiento de la / $-S /$ distensiva.

Datos como los relativos a las formas de tratamiento muestran, precisamente, la transición en el reacomodo del subsistema, y algunos, en sus conformaciones

\footnotetext{
${ }^{26}$ Véase Choy (1999: 51ss).
} 
decimonónicas, como la frecuencia de -se en el pretérito de subjuntivo, o de pues como conector de base causal, reclaman atención más detenida para la datación y la índole de los procesos, a ser posible dentro de las matrices lingüísticas y sociolingüísticas que los condicionan.

Según lo analizado, no podríamos afirmar que estas cartas muestran como promedio una intención explícita de representar la oralidad ${ }^{27}$, sino más bien una conciencia de la índole del texto escrito, que permite explicar los usos arcaizantes. Pero tampoco puede hablarse de una formalización extrema, ni de la estructura ni del lenguaje epistolar, y por ello nos han servido para documentar rasgos conformadores del español cubano, incluso de algunos que, conservados hoy, tienen restricción sociolectal, como la regularización morfológica de la segunda persona singular del pretérito de indicativo.

Los destinadores de estas cartas no son, desde luego, «manos inhábiles», pero en ellos se mantienen inseguridades en el dominio del código que no solo nos ofrecen pistas de los cambios, sino que nos dejan ver que la variedad no ha llegado aún a la plenitud de su transformación.

Considerada hoy entre las modalidades más revolucionarias del español, la cubana se muestra en estas cartas decimonónicas más conservadora, aunque se testimonia la vitalidad de tendencias que operan en la evolución lingüística hispánica desde períodos muy lejanos. Cómo discurre la transición es un problema que continúa reclamando documentos, análisis y pruebas.

\section{REFERENCIAS BIBLIOGRÁFICAS}

AlezA, Milagros y José María Enguita (2002): El español de América: aproximación sincrónica, Valencia, Tirant lo Blanch.

Calsamiglia, Helena y Amparo Tusón (2004): Las cosas del decir. Manual de análisis del discurso, Barcelona, Ariel Lingüística.

CHOY, Luis Roberto (1999): Periodización y orígenes en la historia del español de Cuba, Valencia, Tirant lo Blanch.

\footnotetext{
${ }^{27}$ Para encontrar datos de este tipo habría que remitirse, por ejemplo, a los textos elaborados por El Lugareño, quien hace gala de afectividad, innovación y cubanía, lo que separa mucho sus cartas de las comunes de la época. Precisamente por eso fueron excluidas de este análisis.
} 
DOHOTARU, Puica (2007): «El segmento fonológico - /R/ en el habla popular de la ciudad de La Habana», en Domínguez, M., coord., La lengua en Cuba. Estudios, Santiago de Compostela, Universidad de Santiago de Compostela, 101-145.

DomínguEZ, Marlen (2004): «Evolución histórica de las formas de tratamiento. Análisis de una muestra epistolar en Cuba», Anuario L/L, 35, La Habana, 133-142.

Domínguez, Marlen (2010): La voz de los otros, La Habana, CEM.

ECHENIQUE, M. Teresa (2000): «Sobre los orígenes y evolución del leísmo, laísmo y loísmo», en Cano, R. y M. T. Echenique, eds., Estudios de morfosintaxis histórica del español, Madrid, Gredos, t. 1, 279-310.

FigueroA, Max; Puica Dohotaru y M. T. NoroÑa (1992): «El fonema /-s/ (posición distensiva) en el habla de informantes capitalinos en el nivel universitario», en Cuestionario. Atlas Lingüístico de Cuba, La Habana, Editorial Ciencias Sociales.

Fontanella DE Weinberg, María Beatriz (2000): «Sistemas pronominales de tratamiento en el mundo hispánico», en Bosque, I. y V. Demonte, coords., Gramática descriptiva de la lengua española, Madrid, Espasa, t. 1, 1401-1425.

Frago, J. Antonio y M. Franco (2003): El español de América, Cádiz, Universidad de Cádiz.

GómEZ TORREGO, Leonardo (2000): «La variación en las subordinadas sustantivas: dequeísmo y queísmo», en Bosque, I. y V. Demonte, coords., Gramática descriptiva de la lengua española, Madrid, Espasa Calpe, t. II, 2105-2145.

Gosende, A. (2007). Descripción de los usos ortográficos presentes en una muestra del español de Cuba entre 1750 y 1770, La Habana, Universidad de La Habana, inédito.

GUITART, Jorge (1978): «Aspectos del consonantismo habanero: reexamen descriptivo», Boletín de la Academia Puertorriqueña de la Lengua Española, vol. VI, 96-114.

GutiÉRrez, Alina (2006): Para la descripción lingüística del español en Cuba: usos ortográficos y morfosintácticos en el Papel Periódico de La Havana (1791 y 1794), La Habana, Universidad de La Habana, inédito.

LIPSKI, John (1994): Latin American Spanish, New York, Longman.

LÓPEZ Morales, Humberto (1971). Estudios sobre el español de Cuba, New York, Las Americas Publishing Company.

LÓPEZ MoRALES, Humberto (1992): El español del Caribe, Madrid, MAPFRE.

MONTERO, Lourdes (1990): «Comportamiento de /s/, /r/, /l/ en una zona rural», Anuario L/L, 21, La Habana, 111-138. 
MonTERO, Lourdes (2007) «El español rural de Cuba y su variedad regional», en Domínguez, M., coord., La lengua en Cuba. Estudios, Santiago de Compostela, Universidad de Santiago de Compostela, 147-178.

PONS RoDRíGUEZ, Lola (2010): La lengua de ayer. Manual práctico de Historia del Español, Madrid, Arco/Libros.

Real ACADEMia Española y Asociación de ACAdEMias de la LENGUA ESPAÑOLA (2009): «La derivación apreciativa», Nueva gramática de la lengua española, Madrid, Espasa, 627-662.

RAMíREZ LUENGO, José Luis (2011): La lengua que hablaban los próceres. El español de América en la época de las independencias, Buenos Aires, Voces del Sur.

SÁnCHEZ EsPINOSA, Gabriel (2001): «Madame de Sévigné y la carta familiar en España durante el siglo XVIII», en Boixareu, M. y R. Desné, eds., Recepción de autores franceses de la época clásica en los siglos XVIII y XIX en España y en el extranjero, Madrid, UNED, 111-123.

SÁNCHEZ MÉNDEZ, Juan (2006): «El español de América en el siglo XIX: cinco premisas para su estudio», en Bustos, J. y J. Girón (eds.), Actas del VI Congreso Internacional de Historia de la Lengua Española, Madrid, Arco/Libros, 2337- 2353.

VALDÉS BERNAL, Sergio (1974): «Sobre los indoamericanismos no aruacos en el español de Cuba», Anuario L/L, 5 La Habana, 16-90;

VALDÉS BERNAL, Sergio (1986): La evolución de los indoamericanismos en el español hablado en Cuba, La Habana, Editorial Ciencias Sociales.

VALDÉS BERNAL, Sergio (1990) Inmigración y lengua nacional, La Habana, Editorial Academia.

VALDÉs BERnAL, Sergio (2007): Lengua nacional e identidad cultural del cubano, La Habana, Editorial Félix Varela.

VAQUERO, María (2006): «La formación de las grandes zonas dialectales del español de América», en Bustos, J. y J. Girón, eds., Actas del VI Congreso Internacional de Historia de la Lengua Española, Madrid, Arco/Libros, 3 tomos, 185215. 